\title{
Television Characterizations of Homeless People in the United Kingdom
}

\author{
Darrin Hodgetts* \\ University of Waikato \\ Andrea Cullen \\ University of Waikato
}

\author{
Alan Radley \\ Loughborough University
}

Media link events in society into meaningful plotlines for public consumption. For social issues such as homelessness this storytelling process continues until an issue is resolved or another concern takes precedence. This article investigates British Independent Television News ${ }^{1}$ (ITN) portrayals of homelessness from January 1993 to December $2002(n=99)$. News items are explored as instalments in a larger news narrative through which the public is offered engagements with homeless characters. A quantitative content analysis was used to establish the general prevalence of items throughout the year, story locations, causes and solutions offered for homelessness, and character roles. A qualitative narrative analysis was used to explore the function of these story elements in the overall patterning of the ITN story of homelessness. Of particular note was the promotion of a philanthropic approach to service delivery through the characterization of homeless people as needy victims and the maintenance of estranged relationships between the viewing public and homeless people. The significance of ITN's exclusion of

\footnotetext{
* Correspondence concerning this article should be addressed to Dr. Darrin Hodgetts, Department of Psychology, University of Waikato, Private Bag 3105, Hamilton, New Zealand. [e-mail: dhdgetts@ waikato.ac.nz]

This article presents a media analysis that was conducted as part of a larger investigation of images of homelessness in London. The project was funded by Santory and Toyota Centres for Economics and Related Disciplines and the British Academy. We would like to thank staff from Thames-Reach Bondway and The Passage for their valuable contributions to this project.

${ }^{1}$ ITN is a privately owned broadcaster in direct competition with the BBC, which provides commercial archival services for researchers.
} 
homeless people from public deliberations regarding their needs is discussed in relation to the failure of this wealthy nation to resolve homelessness.

The UK and the United States are saturated with media that provide regular commentaries on social concerns, diagnose interpersonal and intergroup relationships, characterize marginalized groups, and offer prescriptions for addressing social issues. If psychologists are serious about fostering social justice then we need to address the power of such media to identify and frame social issues (Prilleltensky \& Prilleltensky, 2003). Analyses of media are necessary because the resources marginalized groups and communities have to address social inequalities are heavily influenced by public and policy agendas that are often formulated beyond local contexts (Hodgetts, Masters, \& Robertson, 2004). Such analyses allow us to shift our research focus from individual level factors to wider social structures and processes shaping homelessness (Buck, Toro, \& Ramos, 2004). This article interrogates characterizations of homeless people in television news reports and considers the implications of these representations for public responsiveness.

The physical presence of homeless people in the doorways and parks of British towns and cities has rendered the issue of homelessness visible and invoked sustained public concern. News media regularly carry stories about homeless people in which tensions between life and death, caring professionals and needy victims, the "deserving" and "undeserving" poor, and the role of government and the private sector is subject to public scrutiny (Franklin, 1999; Hewitt, 1996; Huckin, 2002). Coverage often describes rates of homelessness, support services, and related problems (Buck, Toro, \& Ramos, 2004). There is a growing body of research attesting to the partiality of such representations (Campbell \& Reeves, 1989; Liddiard \& Huston, 1998). For instance, coverage is highly selective, often maintaining oppositions between "those" homeless people and "us," the housed public. Homeless people are portrayed as different from and often inferior to the housed public, and are subjects of ridicule and punitive control, as well as sympathy and support (Borchard, 2000; Bunis, Yancik, \& Snow, 1996; May, 2003; Whang \& Min, 1999; Widdowfield, 2001). Such depictions are worthy of consideration because public "Knowledge and insight on the lives of homeless people and poor people, in general, is [often] derived from mediated experience, what we read in newspapers, what we hear on radio, what we see on television" (Power, 1999, p. 79). Even when members of the general public are already familiar with homelessness in their own communities, media help them make sense of their experiences and prescribed strategies for their responses to the homeless (May, 2003). Coverage can bind the public within a moral order by providing a sense of coherence to our understandings of homelessness (Bunis, et al., 1996).

These processes are not new because media depictions have reflected the values, politics, and relationships of specific epochs for some time. For instance, 
Wardhaugh (2000) documents how for at least 500 years public values and responses to vagrancy have been communicated to the public via rogue pamphlets, satirical drama, romantic fiction, and the modern press. Mayhew's (1861) seminal work on vagrancy in London documents how Victorian literature framed several notorious vagabonds as folk heroes, while simultaneously stigmatizing the majority of vagrants as lazy and inherently defective "wretches" who require moral instruction in the virtues of work. Throughout recent history policy shifts between philanthropic strategies based on notions of individual rehabilitation and temporary assistance and state-based welfare strategies based on notions of social responsibility and long-term solutions have been communicated through the media (Arapoglou, 2004; Daly, 1997; Smith, 1995). In particular, over the last two decades consecutive monetarist-orientated governments have used the media to espouse the benefits of applying market rationale to the provision of social services. Notions of welfare have been dismissed as simply encouraging dependency, whereas socially responsible businesses and corporate-sponsored provisions were presented as fostering individual responsibility through the provision of "a hand up rather than a hand out" (Franklin, 1999). The result is a complex web of relationships between government, charities, and corporate entities, which maintains inequitable relationships between those who have the power to give and those who must be grateful for what they receive (Arapoglou, 2004; Daly, 1997; Fiske, 1999).

It is important to note that in addition to being influenced by existing political agendas media coverage also influences public policy sentiments (Borchard, 2000; Pleace \& Quilars, 2003). Policies are likely to be developed and implemented if policy makers consider there to be sufficient public support "expressed through" media coverage (Buck et al., 2004; Hodgetts et al., 2004). This raises the importance of symbolic power or the ability of certain groups to access the media and thus influence the framing of homelessness and associated interventions (Shiff, 2003). Such power to name and define homelessness is linked to economic and social privilege. That is, members of more affluent sectors of society such as politicians, celebrities, business people, health professionals, and charity representatives are able to access the media and define the issue. Conversely, economically and socially disadvantaged homeless people are rarely afforded a voice regarding issues affecting their lives and thus face both material and symbolic inequalities (Wright, 2000). An analysis of media representations is crucial for documenting the negotiative processes through which prominent social actors shape the parameters of the debate regarding homelessness and the nature of responses to this pressing social issue.

Briefly, news constitutes a shared symbolic resource for establishing who is homeless, why people are homeless, what happens when a person is homeless, who the experts are, what can be done about this social phenomenon, and who should respond. Previous research into news media representations of homelessness has 
focused primarily on print media as important sites for such collective sensemaking practices (Borchard, 2000; Buck et al., 2004). While remaining underrepresented in the academic literature, television remains particularly pertinent because this medium constitutes a central means through which the plight of distant others is revealed to the wider public (Campbell \& Reeves, 1989). We will document how the presentation of a narrow range of characterizations within television news promotes overly restrained relationships between homeless and housed people, which position the later as sympathetic witnesses to the suffering of the former. In bringing images of homelessness into the domestic realm television simultaneously maintains a "fathomless distance" between homeless and housed people (cf., Cohen, 2001; Simmel, 1908).

\section{The Present Investigation}

When reporting social concerns such as homelessness television news does not simply repeat the same information. The framing of homelessness builds momentum through the emergence of new cases, characters, policies, and research findings. By approaching news coverage as a serial narrative, and not as a series of distinct "items," we can develop a richer understanding of the influence of symbolic power on story trajectories and the framing of policies and social issues (Hodgetts et al., 2004). To this end we trace the framing of homelessness over 10 years of Independent Television News (ITN) coverage.

A search of the ITN archive for items focusing on homelessness in the UK using terms such as rough sleepers, street people, homeless, and housing revealed 123 items broadcast between January 1993 and December 2002. The 99 "Per Actual Broadcast" (PAB) items held by the archive comprise the research corpus.

Our analysis of these items follows what can be referred to as the "text-andcontext" approach (Fiske, 1999; Hodgetts et al., 2004). This analysis moves beyond the description of a story emerging across news items to broader observations about sociocultural processes and relationships underlying such representations (Bunis et al., 1996). This approach reflects Heraclitus' (500 B.C.) assertion that "you can never step into the same river twice" because the flow is in constant flux, as are the social conditions and issues we investigate. Thus, our focus is on the ongoing negotiation of the reality of homelessness through the claims that are made about homeless people and through the portrayal of relationships between key social actors who contribute to media deliberations.

Initially we used a quantitative content analysis to establish general trends across news items. A coding framework was developed to examine both macrolevel themes such as seasonal patterns in coverage and micro-level themes such as interview sources. Specific codes or categories were identified deductively from each author reading the existing research literature and compiling a list of codes. We 
also worked inductively through repeated independent screenings of the research corpus. The coding framework was finalized in an analysis meeting in which we combined our categories and refined the research focus accordingly.

Further details on the coding framework are available from the first author. For now let us briefly mention core categories and how these were employed in the coding process. Settings for the evolving story were coded using camera shots of locations such as streets, parks, charity centers and shelters, and television studios. The causes and solutions offered for homelessness were primarily identified through verbal references to individual and structural factors. Individual level factors, apparently under a person's control, include a lack of personal motivation, substance misuse, and criminal activities. Structural level factors include a shortage of public housing, lack of jobs, and reduced social benefits. Characters in the evolving story were identified through visual depictions illustrating specific actions, uniforms, or locations. Verbal dimensions such as journalists designating roles to onscreen figures were also used. In developing the categories for homeless people we drew on Widdowfield's (2001) three characterizations. First, homeless people were presented as different from the general public. They were cast as abnormal and inferior down and outers. Second, homeless people were presented as criminals whose fraudulent activities and violent actions constituted a threat to civil society. These two characterizations reflect notions of the "undeserving poor." Conversely, the third characterization of homeless people as needy victims reflects notions of the "deserving poor." This characterization was personalized in terms of lost souls or pitiful cases of hardship. We also worked inductively to develop a fourth characterization to account for instances when former homeless people were depicted. The recovered social actor is someone who has "battled the odds" to overcome homelessness and can now return to the street and reflect on his or her previous life on the streets.

To ensure consistency in coding for these categories two of the authors used the general coding guide to independently code 30 randomly selected items. Intercoder reliabilities ranged from $85 \%$ to $90 \%$ for all variables.

Clearly, it is useful to identify such quantitative trends in coverage (Buck et al., 2004; Bunis et al., 1996). It is also necessary to explore how key patterns in coverage are linked meaningfully within storylines by using more context-sensitive qualitative techniques. Due to the rigidity and limitations of quantitative content analysis in dealing with the complexities of media depictions (Ahuvia, 2001), this quantitative analysis was used to support a qualitative analysis of the overall ITN story. When conducting this narrative analysis each author watched the entire corpus again. We then met to discuss the emerging issues and to recontextualize the core trends from the quantitative analysis back into the flow of coverage. A plot synopsis for the story was constructed to capture the function of various narrative elements and characters in the story's progression. 


\section{Analysis of the ITN Story of Homelessness}

\section{A Synopsis of the ITN Story}

From 1993 to 1996 ITN coverage reflected the social advocacy approach to journalism, where journalists responded to the "unanticipated" and harsh implications of reductions in the welfare state. Items emphasized links between increased homelessness and conservative government policies, which resulted in a lack of affordable housing, reduced benefit levels, and deinstitutionalization. As the story developed increased emphasis was placed on what charities were doing to fill the gap left by the retrenchment of the welfare state. At this point charity representatives were increasingly cast in the social advocacy role. Emphasis was placed on educating the public about the extent of homelessness and the negative impact of restraints on welfare spending for homeless people. Along with one-off stories associating homelessness with crime and substance misuse, this general plotline continued from 1997 to 2002 . The first of two interwoven developments related to the change from a Tory government that promoted punitive responses to homelessness to a Labour government that promised more compassionate responses. The second development related to the shift from government to charity representatives as primary initiators of news items. New Labour's policies were initially represented positively. For instance, in a series of items the provision of "new funds" to support the efforts of private charities to respond directly to the needs of local homeless people was presented as a breakthrough in addressing homelessness. However, this support was short lived. As coverage evolved charityinitiated research was used to raise questions regarding the true commitment of New Labour to resourcing such solutions. Particular criticisms were directed at government representatives who proposed more punitive strategies aimed at "uncooperative individuals" or "persistent offenders." Increasingly, charity-initiated items reflected a change in direction from government assistance towards new forms of corporate patronage. In several items London's business elite replaced government representatives as onscreen sponsors of charity initiatives.

The astute reader might ask where homeless characters feature in the progression of this story. The straightforward answer is they are not mentioned in the synopsis because they are not storied as catalysts for the unfolding drama. Homeless people are typecast as pitiful cases that exemplify the plight of hidden homeless families and individuals who "live on the streets." The focus on charitable giving requires the depiction of homeless people as passive illustrations for situations that are to be explained, prevented, and cured through the philanthropic actions of charitable organizations, governments, and private individuals.

The following two sections examine the significance of basic narrative elements to the trajectory of the ITN story, including seasonal patterns in coverage, settings, and causes and solutions offered for homelessness. A focus on these 
contextual elements sets the stage for an engagement with the specific characterizations and relationships offered by ITN.

\section{Story Seasons, Settings, and Solutions}

The framing of homelessness as an issue of philanthropy is reflected in the seasonal nature of coverage, locations in which the story unfolds, and the causes identified and solutions offered for homelessness. Figure 1 indicates that the number of news items peaks in October and December and then drops drastically in January and February ( $c f$. , Borchard, 2000). The end of the year is the traditional season for "good will to all." The ITN story reflects the cultural patterning of the capacity of citizens to sympathize with the plight of other people (Bunis et al., 1996).

A typical item from the Christmas period (Homeless at Christmas, 23 December 1998) opens with a shot of a large warehouse where people are milling around in winter clothing. A journalist introduces the scene as portraying the establishment of a temporary hostel by the charity Crisis. Accompanied by a sequence of images depicting staff shifting supplies and interviews with charity

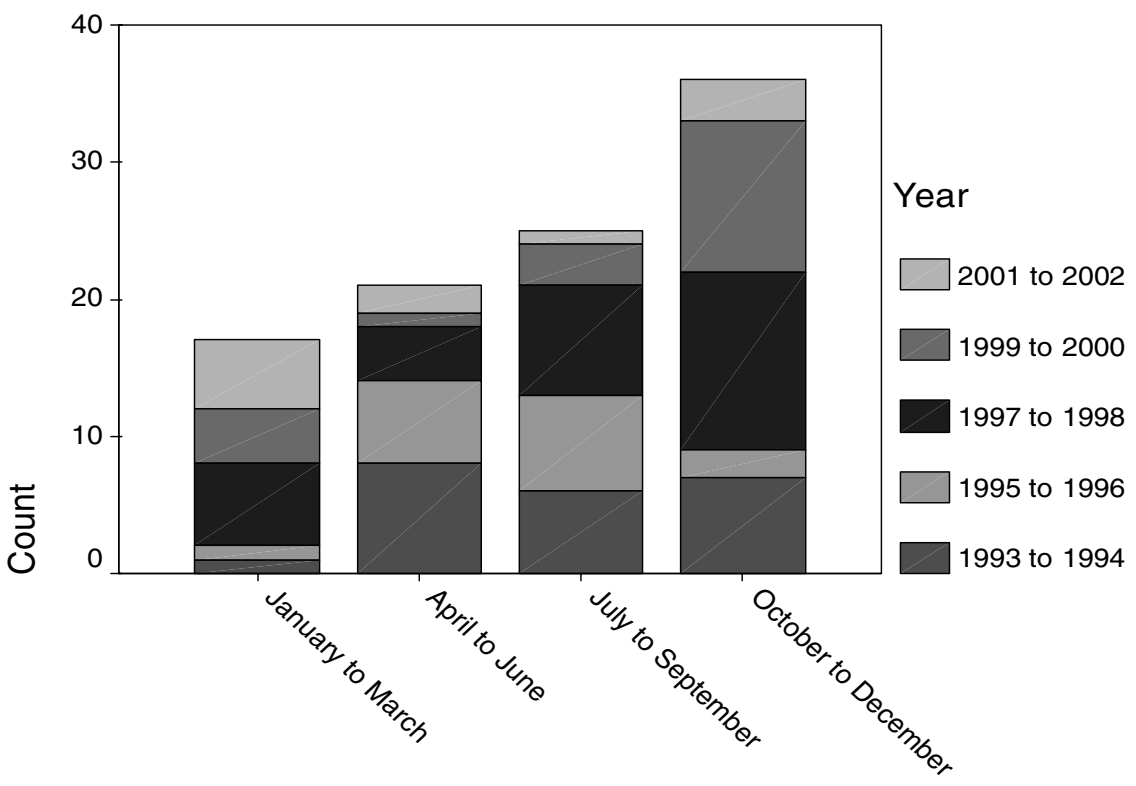

Year (quarterly)

Fig. 1. Seasonal variation in ITN coverage of homelessness $(N=99)$. 
representatives the journalist outlines how a network of shelters is being set up nationally to house homeless people over the Christmas period. This is needed because research indicates that "... throughout the country 10,000 people sleep rough every year..." At this point the camera cuts to the image of a man in a sleeping bag sheltering in a doorway from the rain to visually invoke the need to bring people in from the cold. The street location provides more than a setting for the story. The depiction of individuals on the street on a rainy night with blankets visually renders them homeless and marginal (May, 2003). The characterization of homeless people as vulnerable and in need of sympathy and assistance at this time of year is reinforced with accompanying testimony from journalists and charity and government representatives. For instance, a government representative is depicted at the depot and she states. "We do want to make sure that we give organizations like Crisis the right sort of support so that they can reach out to the most vulnerable at times like this...." The camera then cuts to a soup kitchen and the journalist's voiceover states that "the Crisis Christmas shelters will close on December 30th. There are other projects that will stay open until the end of March...." The item ends with the news anchor reiterating the need for the public to support Crisis at this time of year.

Evident in such items is the way in which ITN overtly appropriates the rhetoric of charitable appeals, including the use of beliefs and sentiments related to seasonal giving that are traditionally epitomized by stories of "no room at the inn" (Franklin, 1999). To emphasize the need for charitable giving as a means of providing "room at the inn," almost half of the 501 locations identified across the 99 items depicted homeless people out in the cold in streets, parks, subways, and under bridges ( $n=240,47.9 \%$ ). Typically, such locations establish the seriousness of homelessness with subsequent sequences illustrating strategies for addressing homelessness being set in charity hostels, drop-in centers, clinics, and Bed \& Breakfasts (B\&B) $(n=117,23.4 \%)$. Homeless people are typically depicted alone on cold streets, and then shown together in warm hostels, receiving food and drink. The combination of street and charity locations frames charitable organizations as primary sites of refuge for homeless people and attempts to regulate "them" both spatially and relationally ${ }^{2}$ (Snow \& Mulcahy, 2001; Wright, 2000).

The juxtapositioning of locations reflects wider seasonal ideas of the family at Christmas. Not to be cold at this time of the year is one thing; not to be alone at Christmas is another. Provision of personal support from housed citizens for the creation of warm spaces for homeless people to participate in Christmas reflects how gift exchange can dramatize group boundaries between our own experiences of Christmas with family and those of homeless people with strangers. Society

\footnotetext{
${ }^{2}$ Such regulation of homeless people is further supported by the absence of homeless people in settings such as government offices or television studios $(n=144,28.7 \%)$, where decisions are made, resources are allocated, and strategies for addressing homelessness are debated.
} 
is served by such images insofar as giving at Christmas helps individuals cope with their own consciences (Bunis et al., 1996). By giving to charities members of the housed public have the opportunity to participate in a shared expression of sympathy toward homeless people and to reaffirm the benevolence of self and society. In this way, this use of settings provides more than locations for telling the story. It reflects underlying assumptions that shape the overall framing of homelessness as an issue worthy of charitable action.

Items such as Homeless at Christmas reflect the increasing primacy of charities in setting the agenda for coverage and the role of government in providing financial support to charities, rather than direct service provisions. This shift is stated succinctly in the closing sequences of an earlier item (New Study, 29 December, 1994) when a journalist states that "Without preaching or problematizing, it's the church picking up where the state leaves off." As was the case with the opening of modern hostels in the 1830s, this support is temporary in that, despite the continued cold weather, shelters often close at the end of the season of good will (Mayhew, 1861). In short, the emphasis being placed on getting homeless people in from the cold at Christmas time could be interpreted as getting homeless people out of the way; a strategy designed to protect the interests of the housed majority (Borchard, 2000; Bunis et al., 1996).

The promotion of a philanthropic approach to homelessness is also reflected in specific patterns of association between causes and solutions for homelessness. When causes and solutions were presented ${ }^{3}$ homelessness was predominantly framed in relation to wider uncertainties surrounding the provision of chartable services. A lack of affordable housing, inadequate temporary accommodation, unemployment, and lack of funding for services were commonly used explanations for homelessness $(n=20,20.2 \%)$ and targets for response $(n=26,26.3 \%)$. Items often combined individual and structural explanations in order to identify causes ( $n=13,13.1 \%)$ and offer solutions $(n=17,17.2 \%)$ for homelessness. Social inequalities are identified as the primary causes for homelessness that must be responded to by the affected individuals and charities. Emphasis is placed on the need to support individuals to cope with adversity and overcome "their" problems in order to rejoin society. Such attribution patterns reflect the realization that homelessness often stems from structural influences intersecting within individual situations (Wagner, 1997): and the portrayal of charities as benevolent societies that attempt to address the "big picture" by lobbying government to fund hostel and rehabilitative schemes.

\footnotetext{
${ }^{3}$ Over half of all items did not identify any causes $(n=61,61.6 \%)$ or solutions $(n=53,53.5 \%)$ for homelessness. At one level this could be interpreted as reflecting the framing of homelessness as a timeless problem that simply exists and must be managed on a day-to-day basis. This interpretation has some currency. However, in the wider context of the evolving ITN story, repeating causes and solutions in every item would be overly redundant.
} 
This framing does not lead to the construction of a story that focuses on the need for social change. Radical interventions to provide long-term affordable housing and community renewal or efforts to alleviate social stressors associated with the risk of homelessness were conspicuous in their absence. Further, there was no consideration of how social and economic restructuring over the 1980s and 1990 s had adversely affected the ability of the state to provide adequate provisions for homeless people:

\footnotetext{
Even structural explanations of homelessness, as a result of lack of housing and health care and of unemployment, remain at a merely descriptive level, lacking substantive political, social, and economic reasons why these structural imbalances exist in the first place (Huth \& Wright, 1997, p. 4).
}

These omissions allow solutions to be individualized in the form of public sympathy toward homeless persons, which can be enacted by charities with donations from the government, members of the public, and private institutions. Such framing works to position homeless people as pitiful one-dimensional characters awaiting charitable assistance. They are not presented as active citizens who have a right to participate in decision-making processes that determine the availability of housing and employment (Fiske, 1999). The following section explores how this framing is manifest through character depictions and relationships in the evolving drama.

\section{Characters in the Evolving Drama}

Like all good tales the ITN story is played out through the actions of a range of colorful characters. The story boasts a cast of 1,864 social actors, of whom $887(47.5 \%)$ are members of the public, $668(36 \%)$ are homeless people, and the remaining $309(16.5 \%)$ are charity representatives, celebrities, government representatives, professionals, and business leaders. The simple prevalence of these characters does not necessarily capture their influence within the story. Characters are located differently and have different roles in the framing of homelessness. For instance, coverage manages tensions arising between homeless people, members of the domicile public, government institutions, and private organizations via speaking protocols. An exploration of such conventions can illuminate the function of symbolic power to the storying of homelessness.

Table 1 identifies interview sources. Given that characters such as charity and government representatives, professionals, celebrities, and business leaders only make up $16.5 \%$ of all characters it is revealing how often they appear as interview sources (Total $n=115,68.1 \%$ ). The shift from state provision to private giving is reflected in charity representatives being the most prevalent sources of expert commentary. Although homeless people were interviewed the second most often, their testimony was limited to the personal implications of adversity, which were deliberated upon by charity and government representatives. The promotion of a 
Table 1. Interview Sources in ITN $(N=99)$

\begin{tabular}{lcr}
\hline & \multicolumn{2}{c}{ Total $(N=169)$} \\
\cline { 2 - 3 } Interview Source & Freq. & 34.9 \\
\hline Charity reps & 59 & 28.4 \\
Homeless people & 48 & 17.2 \\
Government reps & 29 & 8.3 \\
Business reps & 14 & 3.5 \\
Public & 6 & 2.9 \\
Health professionals & 5 & 2.4 \\
Police \& legal reps & 4 & 1.2 \\
Celebrities & 2 & 1.2 \\
Researchers & 2 & \\
\hline
\end{tabular}

detached relationship between homeless people and the viewing public is reflected in how, despite composing the largest body of characters, the public were rarely involved in deliberations regarding homelessness. Members of the public were cast as "extras" who simply occupied public spaces, typically passing homeless people on the street.

Even in isolated cases when homeless people are shown conversing with members of the public testimony from other characters was used to establish the purpose, context, and significance of these brief interactions. For instance, Turner Prize (30/05/1997) focuses on the case of a homeless man who has been entered into the Turner Prize as an artwork that talks to citizens about his experiences of homelessness. The item begins with a depiction of three members of the public in a park outside the Tate Gallery as they listen to this homeless man. The journalist's voiceover states: "It was as an exhibit outside the Tate Gallery that Roger Powel former steel worker and then down and out was attracting the attention of visitors today. He'll eventually be placed inside if he reaches the shortlist of four for the Turner Prize." After the journalist explains the interactive nature of the artwork he interviews Roger outside the Gallery. Roger states: "I am art, yeah. Ah you can get paintings in there where artists can put paint on canvas to bring a point in, but can you talk to that painting? No...." The camera then transports viewers into the world of homelessness through the use of file footage of a group of homeless people sleeping rough under blankets in a littered subway. An accompanying voiceover from the journalist outlines how Roger was "plucked" from "among the homeless ... by his creator Tony Kay. Mr Kay who is in Los Angeles making a film is the nominated artist..." The item transits to the television studio and a graphic of Mr Kay who describes the nature of the entry from Los Angeles. This item ends with Roger walking outside the Gallery as the journalist continues to provide a context for the artwork as an attempt to raise public awareness.

This item exemplifies how homeless people are given one-dimensional roles as the bearers of social disadvantage who exemplify social concerns raised by 
Table 2. Activities Homeless People Perform and Characters They Engage with in ITN Items $(N=99)$

\begin{tabular}{lrr}
\hline Variable & Frequency & Percent \\
\hline Type of activity & & \\
Inactive (sitting in doorways or wandering the street) & 464 & 69.5 \\
Talking to charity or government reps, celebrities, or journalists & 105 & 15.7 \\
Working & 56 & 8.4 \\
Begging & 35 & 5.2 \\
Abusing substances & 8 & 1.2 \\
Homeless person is portrayed with: & & \\
Another homeless person & 286 & 42.9 \\
By themselves & 174 & 26.0 \\
Family members & 65 & 9.7 \\
Charity representative/health professional & 64 & 9.6 \\
Royalty/celebrity & 36 & 5.4 \\
Government representative & 20 & 3.0 \\
Business leaders & 10 & 1.5 \\
Members of the public & 7 & 1.0 \\
Other & 6 & 0.9 \\
\hline
\end{tabular}

members of more powerful social groups. Accounts from homeless people are explained, matched, or contextualized through accounts from journalists, artists, politicians, and charity representatives who observe homelessness from the outside and then communicate their interpretations to the viewing public. This practice limits any potential for homeless people to exert agency over their representations, or contribute to decision making processes. The casting of Roger as the subject of an artwork and not as the artist exemplifies how homeless people are overwhelmingly presented as passive objects of curiosity and benevolence, rather than creative social agents or citizens. Homeless people are recipients of, rather than participants in, the planning and provision of interventions.

Reflecting such character placements, Table 2 presents the activities in which homeless people are engaged in and the characters with whom they interact. Three quarters of the sequences containing images of homeless people aimlessly wandering the streets or sitting in doorways and not interacting with other people. When homeless people were active they told their own stories from the subservient position of the pitiful case to journalists, celebrities, charity workers, health professionals, or business leaders. These simple frequencies reflect the symbolic segregation of homeless people from the housed public. Homeless people occupy another world different from the community of housed taxpayers with whom they only interact in prescribed ways, such as when begging or engaging in prostitution.

Through the combination of specific characterizations the ITN story builds sympathy and support for homeless people as well as retaining stigmatizing images that blame victims for their predicaments (Widdowfield, 2001). For instance, 


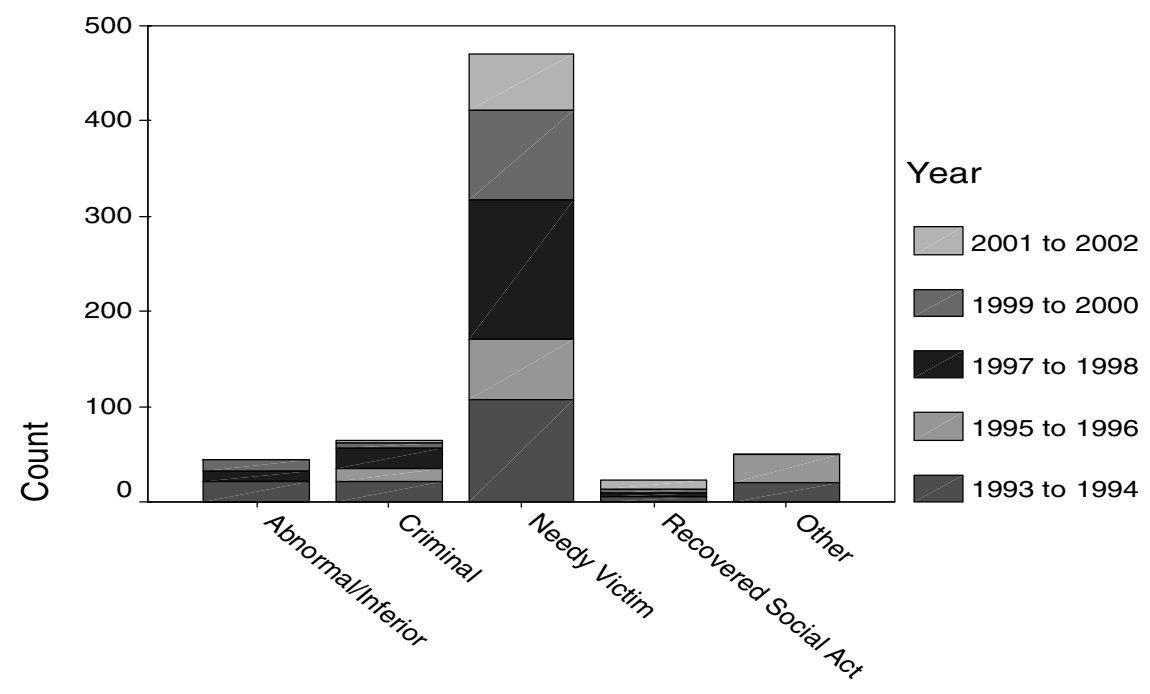

Characterization

Fig. 2. Characterizations of homeless people in ITN $(N=668){ }^{4}$

Figure 2 indicates that the main characterization was the needy victim $(n=470$, $70.4 \%)$. Reliance on this characterization serves to invoke pity and support for homeless people, to exemplify the negative implications of government welfare policies, and to invoke the need for charitable support. This characterization encourages philanthropy because the public is more likely to feel sympathy toward images of needy people who are inactive and dependent, ${ }^{5}$ rather than active, selfdetermining, or threatening (Radley \& Kennedy, 1997). The portrayal of homeless people in hostels, as individuals being helped by others, is also consistent with the idea that vagrants need to be managed, to be brought together into a context that redirects their lives along lines that are socially desirable (Mayhew, 1861; Snow \& Mulcahy, 2001; Wright, 2000).

The focus on helping needy victims foregrounds the need to rehabilitate and thus transform the mass of such needy victims into recovered social actors, who literally embody the success of charitable work. A subtext in the ITN story is that because of the complexities of homelessness and an unsupportive government,

\footnotetext{
${ }^{4}$ The other refers to homeless people who could not be categorized because depictions were only fleeting and were not marked by accompanying commentary.

${ }^{5}$ Only one item from 1993 and one item from 1995 depicted political activism by homeless people. In both cases the activism was only mentioned in passing to exemplify charity-based challenges to "Tory" policies.
} 
recovered social actors are few in number. This serves to justify the need for charities to procure additional resources in order to transform the lives of homeless people. Individual rehabilitation is presented as a panacea for resolving homelessness, which is embodied through the presentation of individual cases (Arapoglou, 2004). The recovery plotline is also ideologically significant because it serves to transform homelessness from an economic issue into a social disease, the cure for which is the cultivation of personal responsibility and motivation through private benevolence. The centrality of this plotline to the construction of homelessness as an issue of philanthropy is epitomized in the Corporate Initiative (26/03/2002). This item reports on corporate efforts to support the recovery of two young homeless men.

Corporate Initiative begins with the portrayal of a London street on a rainy night. One of the men is depicted sleeping in a doorway and then packing up his gear. An accompanying voiceover states:

\footnotetext{
Central London, 5 to 6 in the morning. There's a man in this sleeping bag and his name is Darren Woods. For the past seven months he's spent his nights in this doorway. The milk float or the sound of the dustman his daily alarm call. Darren is 33 from County Durham and homeless. Yet in 3 hours time he will be walking through the door of a FTSE 100 company. This is the story of how he got here.
}

The item shifts to the entrance of an accounting firm as Darren enters the building. The camera is positioned inside the building to visually welcome Darren in from the cold into the world of the working public. Questions regarding "how he got here" are then answered visually when the scene fades to a series of images of business leaders who are traveling with representatives of the charity Business in the Community "... to meet some of the capitals down and outs..." (Journalist's voiceover). This sequence links business leaders, homeless people, and charity efforts in a manner that emphasizes the importance of corporate sponsorship to getting people off the street and into work. Business leaders are shown interacting with young homeless people who explain what it is like to sleep rough and the barriers they face in finding employment and moving off the street. Andrew Deacon is then presented as a homeless youth recently released from prison who responds to questions from the business leaders regarding his "efforts to find work." Andrew states that "There's no point in me asking [for jobs] because I've got nowhere to live ... I've got no bank account ... I couldn't get a job because I couldn't concentrate on it. I've got too many problems on the side that I've got to deal with first." In many respects initial depictions of Andrew reflect the philanthropic contention that "... the young vagrant is the budding criminal," who is inherently lazy and must be taught the virtues of work (Mayhew, 1861, p. 371). However, references to personal hardship and abuse in Andrew's past are used to re-characterize him as a needy victim who requires help to overcome such barriers to employment.

Subsequent depictions of Andrew and Darren participating in corporate sponsored work placements illustrate the positive impact of these business leaders' 
commitment to helping these needy victims find employment. Andrew is depicted interacting with his placement supervisor, who states that Andrew has shown as much commitment as any other staff member. To further exemplify progress in Andrew's recovery the camera provides a series of shots of Andrew in his new flat. The journalist and Andrew explain that this flat was obtained through a referral to the local housing association. Although this is a significant development the journalist's voiceover points out that: “... There's a snag. Andrew still doesn't have a job. His placement at Marshell MacClennon was unpaid and involved changing light bulbs and he left the company very cynical." Andrew then states: "These people haven't really cared about us ... Like it's all either for some free labour because after me there's going to be someone else that's going to do the two-week placement ... Or it's just um like for publicity." This sequence raises potential criticisms of the work placement initiative. However, Andrew's concerns are subordinated to the recovery plotline, which frames his cynicism as reflecting the complexity of the transition from the street to "normal life." Rather than undermining the hegemony of philanthropy, the inclusion of Andrew's concerns adds plausibility to the story and warrants further explanation of these men's lives and the impact of the involvement of corporate leaders.

A strategic return to Darren's case is used to demonstrate how personal perseverance combined with corporate patronage can lead to full-time work and recovery. Bridging both cases, the journalist continues:

The cynicism is understandable. Big British companies give less than half of one percent of their pre-tax profits to community projects and to charity. In the United States it's more than double that. With state provision in retreat the private sector still hasn't grasped that only it can fill the breach.

The camera then cuts to images of business leaders leaving the bus to visit a homeless charity and meeting charity staff as the voiceover continues:

All these business leaders finished their tour of homeless charities with offers of help. They admit they could be accused of tokenism, of corporate window dressing, but in a world obsessed with shareholder value they think that philanthropy might be good for business.

The item ends with a sequence depicting Darren working in an office as the journalist continues to outline how his original placement was followed by a placement at KPMG. He has now been offered full-time work. "And remarkably just a few days ago the company offered him a job paying around $£ 20,000$ a year ..." The camera cuts to an interview with Darren in which he reflects on his transition from life as a needy victim to life as a recovered social actor.

This item exemplifies the shift from charities lobbying government for resources to increased reliance on corporate patronage. Business leaders are cast as heroes coming to the aid of homeless individuals who have been abandoned by the state. In many respects the item is more about the virtues of these business leaders than the virtues of these two homeless men. The focus on the social obligation of 
affluent members of society to engage in voluntary benevolence toward the "less affluent members of society" contributes to the neglect of the well-documented limitations of market provisions for social care (Arapoglou, 2004), and the hidden power relations that are at play in such relationships (Fiske, 1999). Personalizing homelessness through an individual recovery plotline contributes to the neglect of links between the economic system, the creation of needy victims, and the "disposable" resources that companies have to "give." Such transition stories also legitimize wider socio-political shifts in British society where lines of demarcation between public and private spheres have become increasingly "... blurred as forprofit firms take on social welfare functions and as corporations urge their executives and employees to become more involved in such voluntary organizations ..." (Daly, 1997, p. 172).

Certain ideologically significant omissions accompany this corporate sponsored personal recovery plotline. Despite the fact that many homeless people have long work histories ITN relies on the assumption that homeless people need to be taught the value of work and that any work provides positive benefits for people. Such assumptions are not new and in fact were foundational to early responses to vagrancy in the form of workhouses and asylums (Mayhew, 1861). The ITN story also neglects the reality of low-paid occupations, which can be overly coercive and humiliating, offering poverty-level wages, challenging homeless people's sense of dignity and increasing people's risk of mental and physical health problems (Wagner, 1997). Andrew is presented as being overly demanding because he is seeking gainful employment that provides security and a wage that he might actually be able to live on. This response clashes with the common-sense expectation that "beggars can't be choosers." Another reading of Andrew's cynicism is that he may have less of an aversion to work than an aversion to being exploited for the benefit of others. These omissions reflect how ITN promotes a deficit model, where something is wrong with each homeless person and, therefore, guidance is needed to assist individuals overcome "their issues." As a result, attention is diverted from the need to address the social system and life stressors that often lead to homelessness (Wagner, 1997).

\section{Discussion}

Our analysis indicates that ITN works to warrant a shift from public welfare to privately sponsored social care. To support this story frame, ITN relies on simple one-dimensional characterizations of homeless people in situations that fit public expectations. Cast as pitiful cases, homeless people are encouraged to articulate lives that journalists think the public want to hear, and which are translated for public consumption by charity representatives and health professionals. In the process, homeless people are characterized according to the features of their lives that foreground "what they lack" (Wright, 2000). The basis of claims by these 
people to public attention is restricted to their personal problems (Sennett, 2003). Central to such conventions is the lack of space for homeless people to speak beyond restrictive roles. Homeless people are displaced from their own stories. This lack of engagement with homeless people on their own terms raises questions as to whose needs are actually being met by the endless array of new cases, policies, scandals, and interventions. Following Bunis and colleagues (1996) we propose that it is likely to be the housed publics' collective need to ease their consciences by "witnessing" something being done for these unfortunate individuals by heroic charity workers and corporate leaders ( $c f$., Cohen, 2001). We might also conclude that the interests served are those of the groups who have the power to define the issue and select appropriate responses.

Although persistent reliance on depictions of homeless people as needy victims of circumstance who require charitable support is not ideal, one must acknowledge that such depictions are not totally negative. There is a tension here between the potential harm of such restrained caricatures and the need to keep homelessness on the media agenda. Compelling visuals of needy victims waiting in doorways for shelters to open capture the seriousness of homelessness and can build public awareness (Shiff, 2003). Despite these pragmatic considerations we remain concerned about the over reliance on such images. This characterization facilitates the maintenance of fundamentally constrained relationships between the viewing public and homeless people, and the transformation of social ills into personal troubles (Franklin, 1999; Wang \& Min, 1999).

During an epoch in which the welfare state is in decline the actions of charities are fundamentally important. However, the framing of homelessness as an issue of philanthropy toward individual need does have unanticipated consequences. This framing reproduces inequitable social relations between those who have the power to give and those who must receive (Fiske, 1999). As Wright states:

\footnotetext{
... it is not that individual rehabilitation is not important, but rather that such charitable "solutions" are used to frame the debate in such a manner that issues of property, power and wealth never enter the picture - that the substantive economic and political issues are displaced by cultural assumptions that maintain the status quo arrangements of power $(2000$, p. 28).
}

Further, when governments reduce fixed guarantees for support and replace these with temporary acts of charitable aid, efforts to care become increasingly perilous and subject to the whims and public relations ploys of the private sector. Homeless people are also placed at the mercy of the fashionable interests of the housed majority or seasonal patterns of caring (Sennett, 2003). This is reflected in the promotion of sympathetic portrayals during the Christmas period and the tendency for media and the public to ignore the homeless at other times of the year (Buck et al., 2004).

In this article we have documented how ITN promotes the illusion that to observe other people in crisis and to feel sympathetic is sufficient (Borchard, 2000; 
Cohen, 2001). Collective responsibility for action to address the societal causes of homelessness is not promoted. In the process, the general public's engagement with homeless people is transformed from a public engagement between citizens to a private emotional matter that is to be literally experienced in passing. This development resonates with Simmel's (1908) seminal work on the stranger, where repulsion and distance work to maintain forms of engagement in the metropolis that simultaneously brings us together while keeping us apart. It becomes socially acceptable and appropriate for members of the viewing public to keep their distance from vagrants and to leave the responsibility for responding to the needs of homeless citizens to institutions and experts. By containing public involvement in this way the need for social change to address the economic causes of homelessness is nullified (Bunis et al., 1996). As socially orientated psychologists it is up to us to document and challenge the processes of symbolic power that have led to this situation. We can start by working to change media framing of homelessness collaboratively with colleagues from the charity sector who share our concerns and who have cultivated legitimate places from which to speak to the media. After all,

If the future opportunities of the homeless are to brighten, their images within the larger culture must change so that societal reticence to generosity may give way to a level of material support that is consistent with their personal efforts and inherent dignity as human beings (Hill, 2003, p. 136).

Clearly, it would be naïve to propose that homelessness can be resolved through media research and activism alone. However, such work has a part to play in conscientization where we promote alternative characterizations of homeless people that emphasize citizenship in an attempt to foster public understanding and support for collectivist responses. In doing this we should not forget to explore how homeless people themselves respond to media images.

\section{References}

Ahuvia, A. (2001). Traditional, interpretative, and reception based content analysis: Improving the ability of content analysis to address issues of pragmatic and theoretical concern. Social Indicators Research, 52, 139-172.

Arapoglou, V. (2004). The governance of homelessness in the European south: Spatial and institutional contexts of philanthropy in Athens. Urban Studies, 41, 621-639.

Borchard, K. (2000). Fear of and sympathy toward homeless men in Las Vegas. Humanity and Society, 24, 3-18.

Buck, P., Toro, P., \& Ramos, M. (2004). Media and professional interest in homelessness over 30 years (1974-2003). Analyses of Social Issues and Public Policy, 4 (2).

Bunis, W., Yancik, A., \& Snow, D. (1996). The cultural patterning of sympathy toward the homeless and other victims of misfortune. Social Problems, 43, 387-402.

Campbell, R., \& Reeves, J. (1989). Covering the homeless: The Joyce Brown story. Critical Studies in Mass Communication, 6, 21-42. 
Cohen, S. (2001). States of denial: Knowing about atrocities and suffering. Cambridge: Polity Press.

Daly, G. (1997). Charity begins at home: A cross-national view of the voluntary sector in Britain, Canada, and the United States. In M. Huth \& T. Wright (Eds.), International critical perspectives on homelessness (pp. 168-184). London: Praeger.

Fiske, J. (1999). For cultural interpretation: A study of the culture of homelessness. In E. Min (Ed.), Reading the homeless: The media's image of homeless culture (pp. 1-22). London: Praeger.

Franklin, B. (1999). Social policy, the media and misrepresentation (pp. 146-156). London: Routledge.

Hewitt, C. (1996). Estimating the number of homeless: Media misrepresentations of an urban problem. Journal of Urban Affairs, 18, 431-447.

Hill, R. (2003). Homelessness in the US: An ethnographic look at consumption strategies. Journal of Community and Applied Social Psychology, 13, 128-137.

Hodgetts, D., Masters, B., \& Robertson, N., (2004). Media coverage of 'Decades of Disparity' in ethnic mortality in Aotearoa'. Journal of Community and Applied Social Psychology, 14, 455-472.

Huckin, T. (2002). Textual silence and the discourse of homelessness. Discourse \& Society, 13, 347372.

Huth, M., \& Wright, T. (1997). International critical perspectives on homelessness. London: Praeger.

Liddiard, M., \& Hutson, S. (1998). Youth homelessness, the press and public attitudes. Youth and Policy, 59, 57-69.

May, J. (2003). The view from the streets: Geographies of homelessness in the British newspaper press. In A. Blunt (Ed.), Cultural geography in practice (pp. 23-36). London: Arnold.

Mayhew. (1861). London labour and the London poor. London: A cyclopaedia of the condition and earnings of those that will work, those that cannot work, and those that will not work. New York: A. M. Kelly.

Pleace, N., \& Quilars, D. (2003). Led rather than leading? Research on homelessness in Britain. Journal of Community and Applied Social Psychology, 13, 187-196.

Power, G. (1999). Media image and the culture of homelessness: Possibilities for identification. In E. Min (Ed.), Reading the homeless: The media's image of homeless culture (pp. 65-83). London: Praeger.

Prilleltensky, I., \& Prilleltensky, O. (2003). Towards a critical health psychology practice. Journal of Health Psychology, 8, 197-210.

Radley, A., \& Kennedy, M. (1997). Picturing need: Images of overseas aid and interpretations of cultural difference. Culture \& Psychology, 3, 435-460.

Sennett, R. (2003). Respect in a world of inequality. New York: Norton.

Shiff, L. (2003). The power to define: Definitions as a site of struggle in the field of homelessness. Qualitative Studies in Education, 16, 491-507.

Simmel, G. (1908). The stranger. In D. Levine (Ed.), Georg Simmel. On individuality and social forms (pp. 143-149). Chicago: Chicago University.

Smith, J. (1995). The voluntary tradition: Philanthropy and self-help in Britain 1500-1945. In J. Smith, C. Rochester, \& R. Hedley (Eds.), An introduction to the voluntary sector (pp. 9-39). London: Routledge.

Snow, D., \& Mulcahy, M. (2001). Space, politics, and the survival strategies of the homeless. American Behavioral Scientist, 45, 149-169.

Wagner, D. (1997). Reinterpreting the "Undeserving Poor": From pathology to resistance. In M. Huth \& T. Wright (Eds.), International critical perspectives on homelessness (pp. 55-67). London: Praeger.

Wardhaugh, J. (2000). Sub city: Young people, homelessness and crime. London: Ashgate.

Whang, I., \& Min, E. (1999). Blaming the homeless: The populist aspect of network TV news. In E. Min (Ed.), Reading the homeless: The media's image of homeless culture (pp. 121-133). London: Praeger.

Widdowfield, R. (2001). Beggars, blaggers and bums? Media representations of homeless people. The National Academy For The Humanities And Social Sciences Review, January-July, 5153.

Wright, T. (2000). New urban spaces and cultural representations: Social imaginaries, social-physical space, and homelessness. Research in Urban Sociology, 5, 23-57. 
DARRIN HODGETTS is a Senior Lecturer in Community Psychology at the University of Waikato where he teaches courses in Community Health and Media Psychology. Darrin's research explores how people of lower socio-economic status (SES) use shared symbolic resources from the media to construct their views on concerns such as homelessness, social reform, men, aging, and unemployment.

ANDREA CULLEN conducted her doctoral research in the area of the meaning and impact of unemployment. Andrea has worked as a lecturer in Organizational Psychology, practiced psychology in a functional neuro-rehabilitation unit in Canada, provided research consultancy to an organizational development unit in the United Kingdom, and is currently working as a clinical researcher in New Zealand.

ALAN RADLEY is Professor of Social Psychology at the University of Loughborough and founding Editor of the Sage journal 'Health'. Alan's research interests include the social study of health and illness, the role of the body in social life, and compassion as a social response to suffering. 